\title{
EFEITO DA ADUBAÇÃO NITROGENADA NA PRODUÇÃO DE MUDAS DE SETE-CASCAS (Samanea inopinata (Harms) Ducke) ${ }^{1}$
}

\author{
Cezar Augusto Fonseca e $\mathrm{Cruz}^{2}$, Haroldo Nogueira de Paiva ${ }^{3}$ e Cláudio Renato Amadio Guerrero ${ }^{4}$
}

\begin{abstract}
RESUMO - O entendimento da nutrição das mudas e o uso de substratos de cultivo apropriados são essenciais para definição da recomendação adequada de fertilização. Devido à dificuldade de se fazerem recomendações de fertilização específicas, testou-se o efeito da adubação nitrogenada no crescimento e qualidade das mudas de sete-cascas (Samanea inopinata). Foram estudados nove tratamentos com três repetições cada e parcelas com seis sacolas plásticas, em delineamento de blocos ao acaso. A fonte de nitrogênio utilizada foi o sulfato de amônio aplicado sob diferentes dosagens $(0,0,7 ; 1,4 ; 2,1 ;$ e $2,8 \mathrm{~g} / \mathrm{muda})$ a cada 14 ou 28 dias. O experimento foi acompanhado por 12 meses, sendo, então, colhido. Avaliaram-se a altura (H), diâmetro do coleto (D) e matéria seca da parte aérea (MSPA) e da raiz (MSR), calculando-se a matéria seca total (MST) e os índices de qualidade de mudas: H/D, H/MSPA, MSPA/MSR e o IQD. Procedeu-se à análise estatística por análise fatorial e de regressão. Todos os parâmetros morfológicos avaliados foram afetados significativamente, com exceção dos índices MSPA/MSR e H/D. Devido à importância da altura e do diâmetro, recomenda-se aplicar 0,91 g de sulfato de amônio por muda a cada 14 dias, quando cultivadas em Latossolo Vermelho-Amarelo combinado com composto orgânico.
\end{abstract}

Palavras-chave: Nitrogênio, nutrição de plantas, espécies nativas e produção de mudas.

\section{NITROGEN FERTILIZATION ON SETE-CASCAS (Samanea inopinata (Harms) Ducke) SEEDLING PRODUCTION}

\begin{abstract}
Understanding seedling nutrition and the use of appropriate substrata for cultivation are essential to define fertilization recommendations. Due to the difficulty in making specific fertilization recommendations, the effect of nitrogen fertilization was tested on the growth and quality of sete-cascas (Samanea inopinata) seedlings. The experiment consisted of nine treatments with three repetitions each and six plastic bags per parcel, in randomized block design. The nitrogen source was ammonium sulfate applied at different levels every 14 or 28 days. The experiment was monitored for twelve months, and then harvested. The following parameters were evaluated: height $(H)$, root collar diameter $(D)$, dry matter of aerial part (MSPA) and root (MSR), total dry matter (MST) and seedling quality indexes H/D, H/MSPA, MSPA/MSR and IQD were calculated. The data were analyzed using factorial and regression analysis. All the tested morphological parameters were significantly affected by the nitrogen fertilization, except for the MSPA/MSR and H/D indexes. Due to the height and diameter importance, it was recommended $0.91 \mathrm{~g}$ of ammonium sulfate per seedling every 14 days when cultivated in Red-Yellow Latosol, combined with organic compost.
\end{abstract}

Keywords: nitrogen, plant nutrition, native forest species and seedling production.

\footnotetext{
${ }^{1}$ Recebido em 21.01.2005 e aceito para publicação em 05.04.2006.

${ }^{2}$ Programa de Pós-Graduação em Ciência Florestal da Universidade Federal de Viçosa. E-mail: <ceaufoc1@yahoo.com.br>.

${ }^{3}$ Departamento de Engenharia Florestal da Universidade Federal de Viçosa. E-mail: <hnpaiva@ufv.br>.

${ }^{4}$ Curso de Engenharia Florestal da Universidade Federal de Viçosa. E-mail: <guerreroflorestero@yahoo.com>.
} 


\section{INTRODUÇÃO}

Mudas de boa qualidade apresentam maior potencial de sobrevivência e crescimento após o plantio, muitas vezes dispensando o replantio e reduzindo a demanda por tratos culturais de manutenção. Uma muda de boa qualidade deve-se apresentar vigorosa, com folhas de tamanho e coloração típicas da espécie; e ainda em bom estado nutricional. O padrão de qualidade de mudas varia entre as espécies, sendo que o objetivo é alcançar qualidade em que as mudas apresentem capacidade de oferecer resistência às condições adversas que podem ocorrer após o plantio (CARNEIRO, 1995).

Vários fatores afetam a qualidade de mudas, dentre eles se podem citar: qualidade da semente, tipo de recipiente, substrato, adubação e manejo das mudas em geral. Segundo Gonçalves et al. (2000), o bom entendimento da nutrição das mudas e o uso de substratos de cultivo apropriado são fatores essenciais para definição de uma adequada recomendação de fertilização.

Devido ao fato de as espécies nativas da Mata Atlântica possuírem exigências nutricionais bastante distintas entre si, nota-se grande repercussão sobre as diretrizes a serem adotadas no planejamento da fertilização a ser realizada. Tendo em vista esse fato, a fertilização tem sido de fundamental importância na produção de mudas de boa qualidade silvicultural, influindo, assim, na capacidade de adaptação e crescimento.

Existe grande dificuldade de se fazerem recomendações de fertilização específicas para cada espécie, em virtude da grande diversidade de espécies. Dessa forma, têm sido adotadas recomendações que assegurem o suprimento de nutrientes das mais exigentes, tendo, assim, as demais espécies a sua demanda atendida $\mathrm{O}$ aspecto nutricional na produção de mudas deve ser considerado criteriosamente para que as mudas não venham a ter seu crescimento prejudicado pela falta ou desbalanço de nutrientes (GONÇALVES et al., 2000). Os referidos autores ressaltaram ainda que espécies classificadas como pioneiras e secundárias iniciais, por possuírem maiores taxas de crescimento, vão ter por isso mesmo maior demanda por nutrientes e também maior capacidade de absorção e de acumulação de nutrientes nos tecidos vegetais, devendo, então, receber uma recomendação de fertilização mais criteriosa, por vezes mais elevada do que as demais classes.
Segundo Carpanezzi et al. (1976), as informações sobre as exigências nutricionais de espécies florestais, em especial das espécies nativas, são escassas. Brown (1990), citado por Gonçalves et al. (1992), relatou que as espécies pioneiras apresentam maior eficiência nutricional no tocante ao fósforo do que as espécies climácicas, no entanto, com relação ao elemento nitrogênio e ao cálcio, tanto as pioneiras quanto as climácicas têm eficiência nutricional semelhante.

O nitrogênio é o nutriente exigido em maior quantidade pelas culturas, refletindo esse fato no consumo mundial do elemento em fertilizantes que supera há muito as quantidades utilizadas de fósforo ou potássio (RAIJ, 1991).

Uma nutrição nitrogenada adequada automaticamente melhora os teores foliares deste e de outros elementos, especialmente $\mathrm{P}$, aumentando, consequientemente, o crescimento e a produção (BONNEAU et al., 1993, citadoa por BOVI et al., 2002).

A espécie sete-cascas (Samanea inopinata (Harms) Ducke), pertencente à família Leguminosae Mimosoideae, também conhecida como corticeira ou farinha-seca, é uma árvore de grande porte, podendo atingir de 25 a $30 \mathrm{~m}$ de altura e 1,0 m de diâmetro de tronco; copa ampla, com até $30 \mathrm{~m}$ de diâmetro, pouco densa, com folhagem semicaduca (SANTOS, 2000). É uma espécie classificada como secundária inicial com crescimento rápido, apresentando fruto seco. Sua madeira é macia e pouco durável, podendo ser utilizada como forragem. Destaca-se ainda por seu potencial paisagístico e potencial uso na arborização urbana, podendo ser plantada em praças, parques e jardins.

Tendo em vista o potencial da espécie principalmente para a arborização urbana, bem como o fato de não se encontrarem informações a respeito da resposta dessa planta à adubação nitrogenada, o presente trabalho objetivou verificar o efeito da adubação nitrogenada no crescimento e qualidade das mudas de sete-cascas.

\section{MATERIAL E MÉTODOS}

O trabalho foi desenvolvido no Viveiro de Pesquisas do Departamento de Engenharia Florestal, vinculado à Universidade Federal de Viçosa, em Viçosa, MG, no período de abril de 2003 a abril de 2004.

Foram testadas doses de nitrogênio (N) (Quadro 1) nas espécie sete-cascas (Samanea inopinata (Harms) 
Ducke), usando-se como fonte o sulfato de amônio. Como recipiente foram utilizadas sacolas plásticas com capacidade para $3,5 \mathrm{dm}^{3}$ de substrato, sendo este composto por duas partes (volume) de terra de subsolo e uma parte (volume) de composto orgânico produzido com esterco bovino e capim-gordura, substrato este caracterizado quimicamente (Quadro 2).

O solo utilizado para fazer o enchimento das sacolas plásticas foi um Latossolo Vermelho-Amarelo, proveniente de uma área próxima de Viçosa. Foi retirada a camada superficial e usada a camada de subsolo abaixo de 20 $\mathrm{cm}$ de profundidade, que foi secada ao ar e posteriormente peneirada para, então, ser destinada à mistura com composto orgânico e ao enchimento das sacolas.

A semeadura foi feita diretamente nos recipientes já encanteirados, não sofrendo as sementes qualquer tratamento prévio para quebra de dormência. Foi mantida uma cobertura com sombrite $50 \%$ durante duas semanas após a semeadura.

Quadro 1-Dosagem utilizada de sulfato de amônio por tratamento Table 1 -Ammonium sulfate dose per treatment

\begin{tabular}{cc}
\hline Tratamentos & $\begin{array}{c}\text { Dose de Sulfato de Amônio } \\
(\mathrm{g} \text { por muda) }\end{array}$ \\
\hline 1 & 0 (Testemunha) \\
2 & 0,7 a cada 14 dias \\
3 & 0,7 a cada 28 dias \\
4 & 1,4 a cada 14 dias \\
5 & 1,4 a cada 28 dias \\
6 & 2,1 a cada 14 dias \\
7 & 2,1 a cada 28 dias \\
8 & 2,8 a cada 14 dias \\
9 & 2,8 a cada 28 dias \\
\hline
\end{tabular}

A adubação de base constituiu-se de $3 \mathrm{~kg}$ de superfosfato simples por metro cúbico de substrato. A adubação de cobertura foi feita a cada 28 dias, colocando-se $0,58 \mathrm{~g}$ de cloreto de potássio por muda. As doses de fertilizantes utilizadas tanto em cobertura quanto em adubação de base, se basearam na recomendação de Gonçalves et al. (2000), desenvolvida para uso no viveiro florestal da ESALQ e alguns viveiros da CESP.

Os tratamentos foram dispostos em delineamento estatístico de blocos ao acaso, com três repetições e parcelas constituídas por seis sacolas plásticas.

O experimento foi acompanhado pelo período de 12 meses, sendo colhido ao final desse prazo, quando, então, foram avaliados os parâmetros morfológicos altura da parte aérea $(\mathrm{H})$, diâmetro do coleto $(\mathrm{D})$, matéria seca da parte aérea (MSPA), e matéria seca da raiz (MSR). A soma de MSPA com MSR forneceu a matéria seca total (MST). Esses parâmetros foram transformados em índices de qualidade de mudas: H/D, H/MSPA, MSPA/ MSR e o Índice de Qualidade de Dickson (IQD).

O IQD é calculado de forma balanceada, em que se incluem as relações dos parâmetros morfológicos como MST, MSPA MSR, H e D, o qual foi desenvolvido em trabalho realizado com mudas de Picea glauca e Pinus monficola (DICKSON et al., 1960), apresentando a fórmula:

$$
\mathrm{IQD}=\frac{\mathrm{PMST}}{\mathrm{H} / \mathrm{D}+\mathrm{PMSR} / \mathrm{PMSPA}}
$$

De posse desses dados foi procedida a sua análise estatística utilizando o software SAEG, através da aplicação de análise fatorial quando se verificou o efeito dos tratamentos usados sobre as mudas de sete-cascas,

Quadro 2 - Resultado da caracterização química do substrato utilizado no enchimento das sacolas plásticas Table 2 - Chemical characterization of substrate used to fill the plastic bags

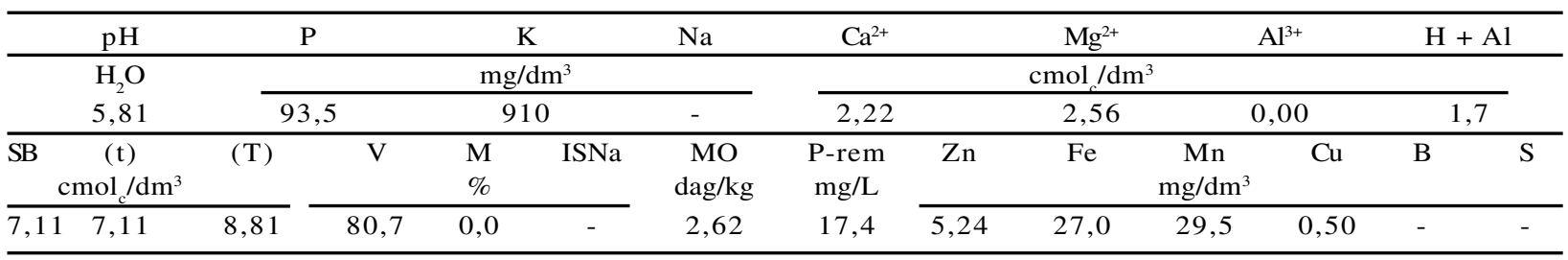

pH em H2O - Relação 1: 2,5 CTC (t) - Capacidade de Troca Catiônica Efetiva P - Na - K - Fe - Zn - Mn - Cu - Extrator Mehlich-1 CTC (T) - Capacidade de Troca Catiônica a pH 7,0 Ca - Mg - Al - Extrator: KCl 1,0 mol/L L V $\mathbf{H + A l}$ - Extrator acetato de cálcio: 0,5 mol/L $(\mathrm{pH}=7,0) \mathbf{~ m}$ - Índice de saturação de alumínio Mat. Org $(\mathrm{MO})=\mathrm{C}$.org.x1,724 - Walkley- Black $\mathbf{P}$-rem = Fósforo Remanescente SB - Soma de bases trocáveis 
bem como foi realizada a análise de regressão dos parâmetros morfológicos e índices de qualidade de mudas.

\section{RESULTADOS E DISCUSSÃO}

As respostas para os diferentes parâmetros morfológicos e índices de qualidade de mudas avaliados neste experimento apresentaram respostas distintas entre si. Os índices MSPA/MSR e H/D não exibiram resposta significativa pela análise fatorial utilizada no trabalho. No Quadro 3 podem ser encontradas as médias obtidas para cada parâmetro morfológico e índices de qualidade de mudas avaliados.

\subsection{Altura da parte aérea}

A altura da parte aérea fornece uma excelente estimativa da predição do crescimento inicial no campo, sendo tecnicamente aceita como uma boa medida do potencial de desempenho das mudas, apesar de que esse parâmetro pode ser influenciado por algumas práticas que são adotadas nos viveiros florestais (MEXAL e LANDS, 1990, citados por GOMES, 2001). No entanto, trata-se de um parâmetro de fácil determinação; não é um método destrutivo, além de sua medição ser muito simples (GOMES et al., 2002).

Para esse parâmetro, a análise fatorial mostrou ter havido resposta significativa das mudas de setecascas à adubação nitrogenada aplicada. As médias encontradas nesse parâmetro morfológico em cada tratamento podem ser vistas no Quadro 3.

A altura apresentou resposta quadrática à aplicação de sulfato de amônio ao substrato a cada 14 dias, tendo seu ponto de máximo na dosagem de $0,65 \mathrm{~g}$ de sulfato de amônio, caindo a partir desse ponto (Figura 1). A máxima altura obtida foi de $94,98 \mathrm{~cm}$ nas mudas, nesse ponto.

Concordando com os resultados obtidos neste trabalho, Silva e Muniz (1995) notaram em seu estudo com mudas de cedro (Cedrela fissilis), cultivadas em solução nutritiva por 110 dias, que a ausência de nitrogênio na solução foi um dos elementos que mais influenciou negativamente o crescimento das plantas. Segundo esses mesmos autores, a deficiência nutricional diminuiu e, posteriormente, estagnou o crescimento das mudas, em relação ao tratamento com todos os nutrientes, tendo isso também ocorrido com Muniz e Silva (1995), ao trabalharem com mudas de perobarosa (Aspidosmerma polyneuron).

Já no mesmo parâmetro morfológico, em que se fizeram adubações a cada 28 dias nas mudas de setecascas, não houve ajuste dos dados ao modelo de regressão calculado, tendo sido não-significativa a resposta encontrada. Essa resposta coincide com o obtido por Nicoloso et al. (2001), trabalhando com mudas de grápia (Apuleia leiocarpa) com 140 dias, em que não verificaram efeito da adubação nitrogenada, quando aplicada isoladamente ou associada a fósforo, sobre a altura das plantas. Segundo esses autores, a espécie demonstra ser medianamente exigente em nitrogênio na sua fase inicial de crescimento quando cultivada em Argissolo Vermelho distrófico arênico.

\subsection{Diâmetro do coleto}

O diâmetro do coleto é facilmente mensurável, não sendo um método destrutivo, sendo considerado por muitos pesquisadores como sendo um dos mais importantes parâmetros para estimar a sobrevivência, logo após o plantio, de mudas de diferentes espécies florestais (GOMES, 2001). No presente trabalho, com relação ao parâmetro diâmetro do coleto, a análise fatorial mostrou ter havido efeito significativo da adubação nitrogenada no crescimento das mudas de sete-cascas. Quando se fez adubação nitrogenada a cada 14 dias, a análise de regressão teve resposta quadrática da aplicação de sulfato de amônio ao substrato sobre o diâmetro do coleto com ponto de máximo em $0,91 \mathrm{~g}$ de sulfato de amônio por muda (Figura 1).

Concordando com o obtido nas mudas de setecascas, Braga et al. (1995) observaram que a omissão de nitrogênio comprometeu o crescimento do diâmetro do caule em mudas de quaresmeira e pereira conduzidas por 100 dias. No entanto, nesse mesmo trabalho, mudas de peroba-rosa que foram conduzidas por 150 dias apresentaram resposta distinta das demais, tendo o fornecimento de nitrogênio reduzido o crescimento em diâmetro das mudas.

Discordando do obtido com as mudas de setecascas, Mendonça et al. (1999), ao trabalharem com mudas de aroeira do sertão conduzidas por 120 dias, verificaram que a omissão de nitrogênio propiciou maior crescimento em diâmetro, tendo essa resposta, no entanto, não diferido estatisticamente da obtida pelos mesmos pesquisadores no tratamento completo. 

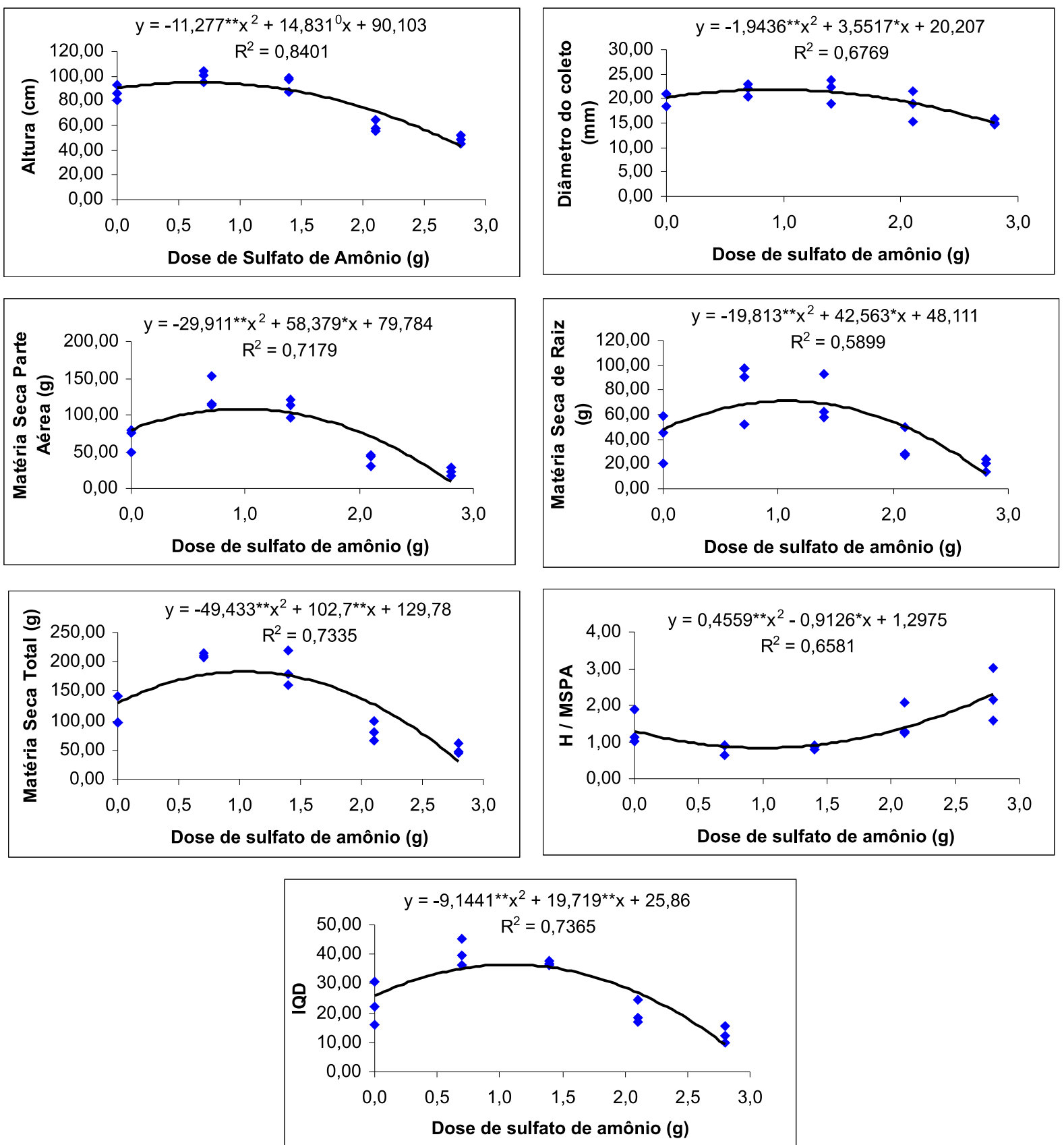

$*$ - significativo a $5 \%$ de probabilidade; $* *$ - significativo a $1 \%$ de probabilidade; ${ }^{0}$ - siginificativo a $10 \%$ de probabilidade

Figura 1 - Dados de altura da parte aérea (H), diâmetro do coleto (D), matéria seca de parte aérea (MSPA), matéria seca de raiz (MSR), matéria seca total (MST) e das relações altura da parte aérea/matéria seca da parte aérea (H/ MSPA) e índice de qualidade de Dickson (IQD), das mudas de sete-cascas em função da adubação nitrogenada a cada 14 dias.

Figure 1 - Data of aerial part height $(H)$, root collar diameter $(D)$, dry matter of aerial part (MSPA), dry matter of root (MSR), total dry matter (MST), aerial part height/ aerial part dry matter ratio (H/MSPA), and Dickson quality index (IQD) of sete-cascas seedlings as a function of nitrogen fertilization every 14 days. 
Quadro 3 - Médias dos parâmetros morfológicos e índices de qualidade de mudas utilizados para verificar a qualidade das mudas de sete-cascas

Table 3 - Means of morphological parameters and seedling quality indexes used to examine sete-cascas seedling quality

\begin{tabular}{|c|c|c|c|c|c|c|c|c|c|}
\hline Altura & Diâmetro & MSPA/MSR & H/MSPA & $\mathrm{H} / \mathrm{D}$ & IQD & & MSPA & MSR & MST \\
\hline (1) 86,61000 & (1) 20,0767 & (1) 2,0146 & (1) 1,3438 & 4,3450 & (1) 23,0335 & (1) & 68,1133 & (1) 41,7700 & (1) 111,8833 \\
\hline (2) 100,1000 & (2) 21,9000 & (2) 1,7830 & (2) 0,8069 & (2) 4,5808 & (2) 40,3870 & (2) & 126,9733 & (2) 80,1033 & (2) 210,0767 \\
\hline (3) 90,4833 & (3) 20,1967 & (3) 1,6355 & (3) 0,9521 & (3) 4,5429 & (3) 31,5236 & (3) & 97,2533 & (3) 62,1867 & (3) 163,4400 \\
\hline (4) 94,2933 & (4) 21,6767 & (4) 1,5878 & (4) 0,8613 & (4) 4,4076 & (4) 36,8885 & (4) & 109,9767 & (4) 71,1900 & (4) 186,1667 \\
\hline (5) 94,8867 & (5) 22,2433 & (5) 1,5303 & (5) 0,8778 & (5) 4,2716 & (5) 39,2791 & (5) & 111,1633 & (5) 78,2867 & (5) 195,4500 \\
\hline (6) 59,0000 & (6) 18,5267 & (6) 1,2242 & (6) 1,5364 & (6) 3,2325 & (6) 19,9456 & (6) & 40,0433 & (6) 35,1100 & (6) 82,1533 \\
\hline (7) 91,7400 & (7) 20,0967 & (7) 1,6938 & (7) 0,9691 & (7) 4,4999 & (7) 32,2864 & (7) & 95,6200 & (7) 60,7467 & (7) 164,3667 \\
\hline (8) 48,5533 & (8) 15,1467 & (8) 1,2393 & (8) 2,2531 & (8) 3,2095 & (8) 12,6570 & (8) & 22,7767 & (8) 19,0667 & (8) 50,8433 \\
\hline (9) 89,3000 & (9) 18,9667 & (9) 2,0387 & (9) 1,1552 & (9) 4,7148 & (9) 25,6129 & (9) & 79,0067 & (9) 48,1867 & (9) 137,1933 \\
\hline
\end{tabular}

MSPA/MSR - Relação matéria seca de parte aérea dividida por matéria seca de raiz H/MSPA - Relação altura dividida pela matéria seca de parte aérea H/D - Relação altura dividida pelo diâmetro do coleto

MSPA - Matéria seca de parte aérea MSR - Matéria seca de raiz

IQD - Índice de Qualidade de Dickson

No presente trabalho, as mudas que receberam adubação nitrogenada a cada 28 dias, a análise de regressão apontou que houve resposta quadrática à aplicação de sulfato de amônio ao substrato, tendo o ponto de máximo diâmetro do coleto sido atingido quando da aplicação de 1,23 g de sulfato de amônio por muda (Figura 2).

Ao contrário do constatado nas mudas de setecascas, Duboc et al. (1996) notaram que a omissão de nutrientes, entre eles o nitrogênio, mostrou-se mais importante para o crescimento em altura do que em diâmetro das plantas de óleo-copaíba. Segundo esses mesmos autores, o diâmetro diferentemente da altura não foi afetado pela omissão de nitrogênio.

Para a espécie sete-cascas, o maior valor de diâmetro de coleto obtido nos tratamentos em que se realizaram adubações a cada 14 dias foi de 21,83 mm contra 21,30 $\mathrm{mm}$ nos tratamentos com adubações a cada 28 dias, considerando-se o ponto de máximo.

\subsection{Matéria Seca de Parte Aérea}

A análise fatorial indicou ter havido efeito significativo da aplicação de sulfato de amônio nas mudas de sete-cascas em relação à produção de matéria seca da parte aérea. Nos tratamentos em que se realizaram aplicações de sulfato de amônio a cada 14 dias, a análise de regressão mostrou resposta quadrática, tendo obtido o ponto de máxima produção de matéria seca de parte aérea, quando da dose de $0,98 \mathrm{~g}$ de sulfato de amônio por muda (Figura 1), alcançando um valor de 108,27 g. Confirmando o efeito positivo da adubação nitrogenada na produção de mudas, Braga et al. (1995) relataram que a produção de matéria seca de parte aérea de plantas de quaresmeira foi comprometida à época da omissão de nitrogênio, reduzindo significativamente a biomassa da parte aérea de plantas de pereira também. Esses mesmos autores destacaram ainda em seu trabalho que o crescimento da parte área de Acacia mangium foi muito reduzido pela omissão de nitrogênio, tendo sido, no entanto, o fósforo o nutriente mais limitante.

No caso das mudas de sete-cascas quando da adubação a cada 28 dias, houve resposta significativa das mudas à aplicação de sulfato de amônio na produção de matéria seca de parte aérea, apresentando resposta quadrática, conforme se pode verificar no gráfico obtido para esse parâmetro, alcançando ponto de máximo na dose de 1,48 g de adubo por muda (Figura 2), com uma produção de 107,63 g. Em concordância com o obtido neste trabalho, Duboc et al. (1996), trabalhando com mudas de óleo-copaíba, observaram que a omissão de nitrogênio, bem como de fósforo, afetou o particionamento da matéria seca entre a parte aérea e o sistema radicular, com maior mobilização de reservas para as raízes do que para a parte aérea. No entanto, Nicoloso et al. (2001) não encontraram resposta positiva à aplicação de nitrogênio, isoladamente ou associado ao fósforo, tendo, entretanto, notado que, aplicado junto com o potássio, proporcionou incremento significativo para mudas de grápia. Eles destacaram que a grápia demonstra ser uma planta medianamente exigente em nitrogênio na sua fase inicial de crescimento, quando cultivada em Argissolo Vermelho distrófico arênico. 

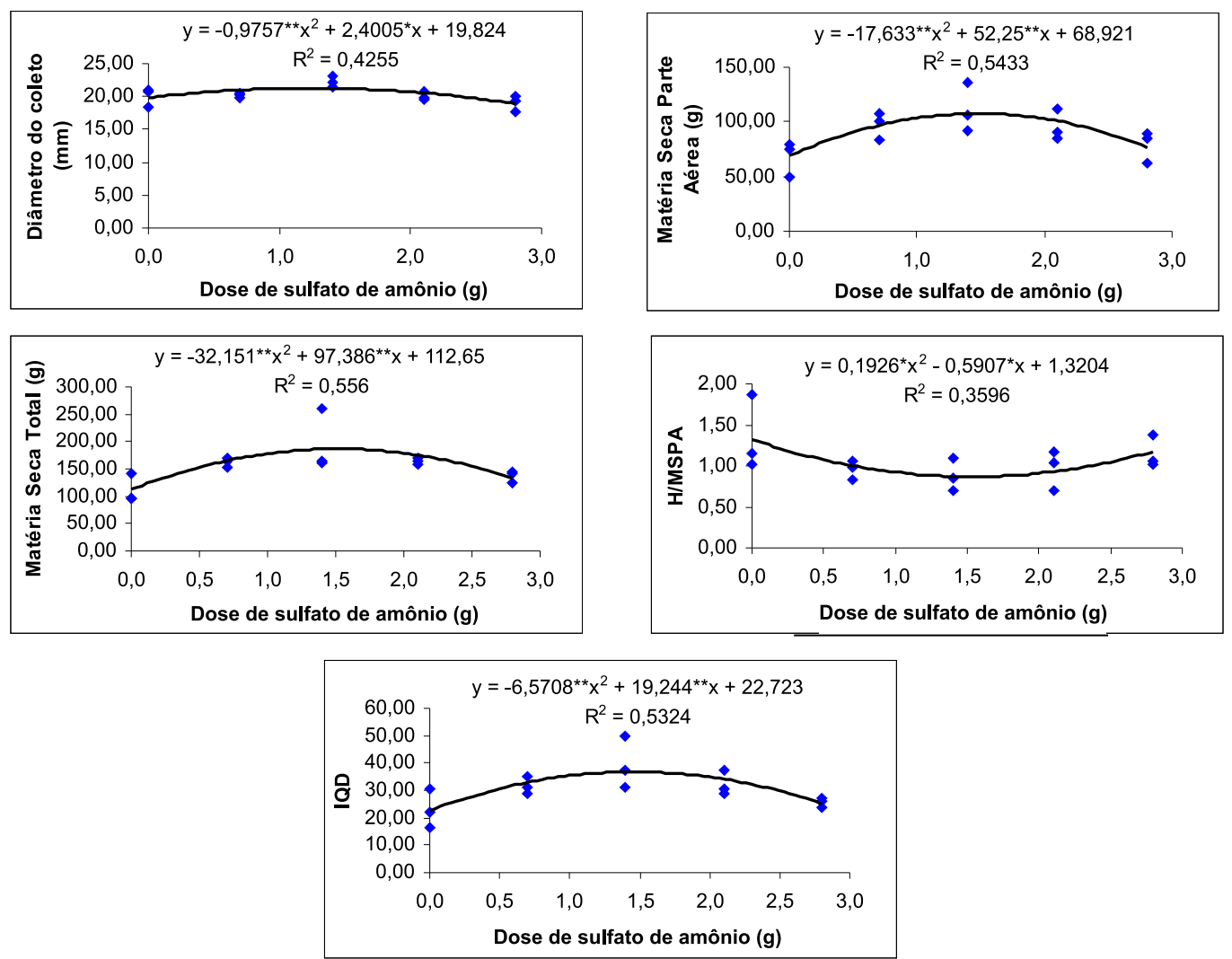

* - significativo a $5 \%$ de probabilidade; $* *$ - significativo a $1 \%$ de probabilidade; ${ }^{0}$ - siginificativo a $10 \%$ de probabilidade

Figura 2 - Dados de diâmetro do coleto (D), matéria seca da parte aérea (MSPA), matéria seca total (MST) e das relações altura da parte aérea/matéria seca da parte aérea (H/MSPA) e índice de qualidade de Dickson (IQD), das mudas de sete-cascas em função da adubação nitrogenada a cada 28 dias.

Figure 2 - Data of root collar diameter (D), dry matter of aerial part (MSPA), total dry matter (MST), aerial part height/ aerial part dry matter ratio (H/MSPA) and Dickson quality index (IQD) of sete-cascas seedlings as a function of nitrogen fertilization every 28 days.

A exemplo do ocorrido para o diâmetro do coleto, o valor máximo de produção de matéria seca de parte aérea pelas mudas de sete-cascas utilizadas neste trabalho foi praticamente o mesmo nos dois intervalos de tempo de aplicação do adubo.

\subsection{Matéria Seca de Raiz}

O peso de matéria seca das raízes tem sido reconhecido por diferentes autores como sendo um dos mais importantes e melhores parâmetros para se estimar a sobrevivência e o crescimento inicial das mudas no campo (GOMES, 2001). No caso da espécie utilizada neste estudo, a análise fatorial mostrou ter havido resposta significativa da adubação nitrogenada com sulfato de amônio nas mudas de sete-cascas, quanto à produção de matéria seca de raiz.

Nos tratamentos em que se realizaram adubações a cada 14 dias, a análise de regressão apontou resposta quadrática à aplicação de sulfato de amônio ao substrato de cultivo das mudas, tendo sido atingido o ponto de máxima produção de matéria seca de raiz na dose estimada de 1,07 g de adubo por muda (Figura 1), sendo que nos tratamentos com adubações a cada 28 dias a análise de regressão não apresentou ajuste adequado para os valores de médias obtidos nos tratamentos utilizados. Da mesma forma que o obtido no presente trabalho com as mudas de sete-cascas adubadas a cada 14 dias, Venturin et al. (1999), trabalhando com mudas 
de angico-amarelo, observaram que o sistema radicular das plantas foi significativamente afetado pela omissão de nutrientes, sendo um destes o nitrogênio, além do fósforo, enxofre e cálcio, tendo havido menor produção de matéria seca de raiz no tratamento com omissão de nitrogênio em relação ao tratamento completo.

Já Mendonça et al. (1999) observaram, em mudas de aroeira do sertão, que o valor obtido de peso de matéria seca de raiz no tratamento com omissão de nitrogênio foi estatisticamente semelhante ao obtido no tratamento completo, ao contrário de Braga et al. (1995), que verificaram que o crescimento radicular da A. mangium foi muito reduzido pela omissão de nitrogênio, mesmo tendo sido o fósforo o nutriente mais limitante. Esses mesmos autores notaram ainda que, para peroba-rosa, o suprimento principalmente de nitrogênio reduziu a matéria seca radicular. Já nas plantas de quaresmeira a produção de matéria seca de raízes foi comprometida pela omissão do nutriente.

\subsection{Matéria Seca Total}

Nos tratamentos que receberam adubações a cada 14 dias, foi detectado efeito significativo da aplicação de sulfato de amônio, apresentando resposta quadrática, tendo ponto de máximo de 1,04 g por muda (Figura 1). Nos tratamentos em que as mudas de sete-cascas receberam adubações com sulfato de amônio a cada 28 dias, a análise de regressão demonstrou haver resposta quadrática das mudas à adubação, com ponto de máximo em 1,51 g (Figura 2).

Ao contrário do obtido nas mudas da espécie utilizada nesta pesquisa, Nicoloso et al. (2001), trabalhando com mudas de grápia, notaram que a massa seca total da planta apresentou resposta semelhante àquela observada na massa seca das folhas no referido experimento, ou seja, não se verificou resposta à aplicação de nitrogênio isoladamente ou associado ao fósforo, tendo, no entanto, proporcionado incremento significativo quando da aplicação com o potássio. No entanto, mudas de $A$. mangium responderam positivamente à aplicação de nitrogênio ao substrato, tendo propiciado consideráveis aumentos na produção de matéria seca das plantas de uma maneira geral (DIAS et al., 1991), concordando com o resultado apresentado pelas mudas de sete-cascas.

Neste trabalho, para as mudas da espécie estudada foi estimado um valor de peso de matéria seca total de 183,12 g para a dose de máxima produção com adubações a cada 14 dias, enquanto na dose de máxima produção com adubações a cada 28 dias foi obtido o valor de 186,40 g. Deve-se considerar que, quanto maior for esse valor, melhor será a qualidade das mudas produzidas.

\subsection{Relação Altura por Diâmetro (H/D)}

O valor resultante da divisão da altura da parte aérea de uma muda pelo respectivo diâmetro do coleto exprime um equilíbrio de crescimento, relacionando esses dois importantes parâmetros morfológicos num só índice (CARNEIRO, 1995). A análise fatorial aplicada para avaliação da resposta desse índice de qualidade de mudas à adubação nitrogenada indicou não ter havido resposta significativa dele à aplicação de sulfato de amônio nas mudas de sete-cascas.

O menor valor obtido desse índice de qualidade foi de 3,20 para as mudas de sete-cascas (Quadro 3), sendo recomendado que, quanto menor for o seu valor, maior será a capacidade de as mudas sobreviverem e se estabelecerem na área de plantio definitivo (CARNEIRO, 1983a, citado por GOMES, 2001).

\subsection{Relação Altura da Parte Aérea pelo Peso de Matéria Seca da Parte Aérea}

Segundo Gomes (2001), o quociente obtido pela divisão da altura da parte aérea pelo peso de matéria seca da parte aérea não é comumente usado como um índice para avaliar o padrão de qualidade de mudas, mas pode ser de grande valia se utilizado, principalmente, para predizer o potencial de sobrevivência da muda no campo. No presente experimento, a análise fatorial evidenciou ter havido resposta significativa desse índice de qualidade de mudas à adubação nitrogenada com sulfato de amônio.

A análise de regressão dos tratamentos que receberam aplicação de sulfato de amônio a cada 14 dias apontou efeito significativo da adubação das mudas, tendo ocorrido resposta quadrática com ponto de mínimo quando da aplicação de $1,00 \mathrm{~g}$ de sulfato de amônio por muda (Figura 1). Já nos tratamentos em que as mudas de sete-cascas foram submetidas à aplicação de sulfato de amônio a cada 28 dias foi detectada através da análise de regressão, resposta quadrática à adubação, tendo sido obtido um ponto de mínimo quando da dose de 1,53 g de sulfato de amônio por muda (Figura 2). 
De acordo com Gomes (2001), quanto menor for esse índice mais lenhificada, será a muda e maior deverá ser a sua capacidade de sobrevivência no campo. No caso das mudas de sete-cascas utilizadas no presente trabalho, o menor valor para esse índice foi de 0,84 nas adubações realizadas a cada 14 dias, enquanto nas adubações realizadas a cada 28 dias foi de 0,87 (Quadro 3).

\subsection{Relação Matéria Seca de Parte Aérea por Matéria Seca de Raiz}

Para as mudas de sete-cascas, a análise fatorial mostrou não ter havido resposta significativa da adubação nitrogenada sobre esse índice de qualidade de mudas.

Para Pinus taeda, P. elliotti, P. echinata e P. palustris, a importância dessa relação foi confirmada, sendo os seus valores determinados entre 1,0 e 3,0 (WAKELEY, 1954, citado por GOMES, 2001). Brissette (1984) afirmou que num encontro de pesquisadores ficou estabelecido como sendo 2,0 a melhor relação entre o peso de matéria seca da parte aérea e o respectivo peso de matéria seca de raiz. Para as mudas de setecascas, espécie adotada no presente trabalho, os valores obtidos para este índice de qualidade variaram entre 2,04 e 1,22 (Quadro 3).

\section{9. Índice de Qualidade Dickson (IQD)}

Gomes (2001) afirmou que o IQD é uma fórmula balanceada, em que se incluem as relações dos parâmetros morfológicos como MST, MSPA MSR, H e D, tendo esse índice de qualidade sido desenvolvido por Dickson et al. (1960), trabalhando com mudas de Picea glauca e Pinus monficola. No presente trabalho, a análise fatorial mostrou ter havido resposta significativa desse índice de qualidade de mudas à adubação nitrogenada aplicada nas mudas de sete-cascas.

A análise de regressão dos tratamentos que receberam adubações a cada 14 dias apontou haver resposta quadrática à aplicação de sulfato de amônio durante o cultivo das mudas, tendo ponto de máximo em 1,08 g (Figura 1). No caso dos tratamentos que receberam adubações a cada 28 dias, também foi detectada, pela análise de regressão, resposta significativa, sendo esta quadrática com o ponto de máximo na dose de $1,46 \mathrm{~g}$ de sulfato de amônio por muda (Figura 2).
O maior valor encontrado para esse índice de qualidade de mudas foi obtido com as aplicações de sulfato de amônio a cada 14 dias nas mudas de setecascas, tendo se calculado um valor de 36,49 desse índice nesse tratamento, enquanto nas adubações a cada 28 dias se obteve um valor de 16,81. Segundo Gomes (2001), quanto maior o valor desse índice, melhor o padrão de qualidade das mudas.

\section{CONCLUSÕES}

A adubação nitrogenada com sulfato de amônio afetou significativamente todos os parâmetros morfológicos avaliados no trabalho, porém de maneira distinta, com exceção dos índices matéria seca de parte aérea por matéria seca de raiz (MSPA/MSR) e altura da parte aérea por diâmetro do coleto (H/D).

Os valores de máxima altura da parte aérea, diâmetro do coleto e produção de matéria seca, bem como dos índices de qualidade de mudas utilizados, diferem entre si no que se refere às diferentes épocas testadas no presente trabalho (14 e 28 dias).

Os melhores valores dos parâmetros morfológicos altura da parte aérea, diâmetro do coleto, matéria seca da parte aérea e matéria seca de raiz, bem como das relações H/MSPA e do Índice de Qualidade de Dickson (IQD), são obtidos para adubações a cada 14 dias, enquanto no parâmetro produção de matéria seca total o melhor valor é obtido para adubações a cada 28 dias.

Dado que para a produção de mudas para arborização urbana são considerados mais importantes na avaliação da qualidade das mudas produzidas a altura destas, bem como o diâmetro do coleto recomenda-se a aplicação de $0,91 \mathrm{~g}$ de sulfato de amônio por muda a cada 14 dias para mudas de sete-cascas cultivadas em Latossolo Vermelho-Amarelo, combinado com composto orgânico.

\section{REFERÊNCIAS BIBLIOGRÁFICAS}

BOVI, M. L. A.; GODOY Jr., G.; SPIERING, S. H. Respostas de crescimento da pupunheira à adubação NPK. Scientia Agricola, v. 59, n. 1, p. 161-166, 2002.

BRAGA, F.A. et al. Exigências nutricionais de quatro espécies florestais. Revista Árvore, v. 19, n. 1 , p. 18-31, 1995.

R. Árvore, Viçosa-MG, v.30, n.4, p.537-546, 2006 
BRISSETTE, J. C. Summary of discussions about seedling quality. In: SOUTHERN NURSERY CONFERENCES, 1984, Alexandria. Proceedings... New Orleans: USDA. Forest Service. Southern Forest Experiment Station, 1984. p. 127-128.

CARnEIRo, J.G.A. Produção e controle de qualidade de mudas florestais. Curitiba: Universidade Federal do Paraná, 1995. 451p.

CARPANEZZI, A. A. et al. Teor de macro e micronutrientes em folhas de diferentes idades de algumas espécies florestais nativas. Anais da E.S.A. "Luiz de Queiroz", v. 23, p. 225-232, 1976.

DIAS, L. E.; ALVAREZ, V. H.; BRIENZA Jr., S. Formação de mudas de Acacia mangium Willd: 2. Resposta a nitrogênio e potássio. Revista Árvore, v. 15, n. 1, p. 11-22, 1991.

DICKSON, A.; LEAF, A. L.; HOSNER, J. F. Quality appraisal of white spruce and white pine seedling stock in nurseries. Forestry Chronicle, v. 36, p. 10-13, 1960 .

DUBOC, E. et al. Fertilização de plântulas de Copaifera langsdorffii Desf. (Óleo Copaíba). Revista Cerne, v. 2, n. 2, p. 1-17, 1996.

GOMES, J. M. Parâmetros morfológicos na avaliação da qualidade de mudas de Eucalyptus grandis, produzidas em diferentes tamanhos de tubete e de dosagens de N-P-K. 2001. 126f. Tese (Doutorado em Ciência Florestal) - Universidade Federal de Viçosa, Viçosa, 2001.

GOMES, J.M. et al. Parâmetros morfológicos na avaliação da qualidade de mudas de Eucalyptus grandis. Revista Árvore, v. 26, n. 6, p. 655-664, 2002.

GONÇALVES, J. L. M. et al. Capacidade de absorção e eficiência nutricional de algumas espécies arbóreas tropicais. In: CONGRESSO NACIONAL SOBRE ESSÊNCIAS NATIVAS, 2., 1992, São Paulo. Anais... São Paulo: Instituto Florestal, 1992. p. 463-468.

R. Árvore, Viçosa-MG, v.30, n.4, p.537-546, 2006
GONÇALVES, J. L. M. et al. Produção de mudas de espécies nativas: substrato, nutrição, sombreamento e fertilização. In: GONÇALVES, J. L. M.; BENEDETI, V. (Eds.). Nutrição e fertilização florestal. Piracicaba: IPEF, 2000. p. 309-350.

MENDONÇA, A. V. R. et al. Exigências nutricionais de Myracrodruon urundeuva Fr. A1l. (Aroeira do Sertão). Revista Cerne, v. 5, n.1, p. 65-75, 1999.

MUNIZ, A. S.; SILVA, M. A. G. Exigências nutricionais de mudas de peroba-rosa (Aspidosperma polyneuron Muller Argoviensis) em solução nutritiva. Revista Árvore, v. 19, n. 2, p. 263-271, 1995.

NICOLOSO, F. T.; FOGAÇA, M. A. F.; ZANCHETTI, F.; MISSIO, E. Nutrição mineral de mudas de Grápia (Apuleia leiocarpa) em argissolo vermelho distrófico arênico: (1) Efeito da adubação NPK no crescimento. Ciência Rural, v. 31, n. 6, p. 1-8, 2001.

RAIJ, B. Van. Fertilidade do solo e adubação. São Paulo: Ceres, Piracicaba: POTAFOS, 1991.343 p.

SANTOS, E. Avaliação quali-quantitativa da arborização e comparação econômica entre a poda e a substituição da rede de distribuição de energia elétrica da região administrativa centro-sul de Belo Horizonte-MG. 2000. 219f. Tese (Doutorado em Ciência Florestal) - Universidade Federal de Viçosa, Viçosa, 2000.

SILVA, M. A. G.; MUNIZ, A. S. Exigências nutricionais de mudas de cedro (Cedrela fissilis Velloso) em solução nutritiva. Revista Árvore, v. 19, n. 3, p. 415-425, 1995.

VENTURIN, N. et al. Adubação mineral do angico amarelo (Peltophorum dubium) (Spreng) Taub.). Pesquisa Agropecuária Brasileira, v. 34, n. 3, p. 441-448, 1999. 